\title{
Conservation agriculture increases soil organic carbon and residual water content in upland crop production systems
}

\author{
Victor B. Ella a, Manuel R. Reyes b, Agustin Mercado, Jr.c, \\ Adrian Ares d,*, Rafael Padre a
}

a Land and Water Resources Division, Institute of Agricultural Engineering, College of Engineering and Agro-industrial Technology, University of the Philippines Los Baños, Laguna Philippines

b North Carolina A\&T State University, North Carolina, USA

c World Agroforestry Center, Claveria, Philippines

d Office of International Research, Education and Development, Virginia Tech, USA

\section{Article Info}

Received : 02.01.2015

Accepted : 12.07.2015

\begin{abstract}
Conservation agriculture involves minimum soil disturbance, continuous ground cover, and diversified crop rotations or mixtures. Conservation agriculture production systems (CAPS) have the potential to improve soil quality if appropriate cropping systems are developed. In this study, five CAPS including different cropping patterns and cover crops under two fertility levels, and a plow-based system as control, were studied in a typical upland agricultural area in northern Mindanao in the Philippines. Results showed that soil organic carbon (SOC) at $0-5-\mathrm{cm}$ depth for all CAPS treatments generally increased with time while SOC under the plow-based system tended to decline over time for both the high $\left(120,60\right.$ and $\left.60 \mathrm{~kg} \mathrm{~N} \mathrm{P} \mathrm{K} \mathrm{ha}{ }^{-1}\right)$ and moderate (60-30-30 kg N P K ha-1) fertility levels. The cropping system with maize + Stylosanthes guianensis in the first year followed by Stylosanthes guianensis and fallow in the second year, and the cassava + Stylosanthes guianensis exhibited the highest rate of SOC increase for high and moderate fertility levels, respectively. After one, two, and three cropping seasons, plots under CAPS had significantly higher soil residual water content (RWC) than under plow-based systems. Results of this study suggest that conservation agriculture has a positive impact on soil quality, while till systems negatively impact soil characteristics.
\end{abstract}

Keywords: Upland agriculture, soil quality, climate change adaptation, cropping systems

(C) 2016 Federation of Eurasian Soil Science Societies. All rights reserved

\section{Introduction}

The sustainability of upland crop production systems depends to a large extent on soil quality, which is affected by the nature of the farming system being implemented. In many parts of the Philippines, plowbased agriculture systems continue to be practiced, leading to serious soil degradation, especially on steep terrain. Plowing causes loss of soil organic carbon (SOC) because of greater exposure of the soil particles to microbial activity (de Morais, 2011). The loosening of the soil particles in plow-based systems may also decrease the soil residual water retention. This disruption causes carbon-protecting aggregates to disperse, a process further accelerated by cycles of wetting and drying and exposure to precipitation (Balesdent et al., 2000). Furthermore, plow-based systems increase the cost of agricultural crop production in the mediumand long-term because greater amounts of fertilizer inputs, soil amendments, and other inputs are needed to compensate for the degradation of soil quality. Traditional agricultural practices trigger excessive soil erosion and sedimentation of natural streams, reduction in channel capacities, and flooding. Adverse environmental impacts on soil quality have become even more pronounced in recent years with the

\footnotetext{
${ }^{*}$ Corresponding author.

Office of International Research, Education and Development, Virginia Tech, 526 Prices Fork Road, Blacksburg, VA, 24061, USA

Tel.: +15406295875

E-mail address: crdesf@yahoo.com

e-ISSN: $2147-4249$

DOI: http://dx.doi.org/10.18393/ejss.2016.1.024-029
} 
occurrence of extreme rainfall events, presumably caused by climate change (Meehl et al., 2007; Follet et al., 2012).

Conservation agriculture involves minimum soil disturbance, continuous ground cover, and diversified crop rotations or mixtures (Erenstein et al., 2008). It is currently implemented in more than 110 million ha in countries such as the United States, Canada, Brazil, Argentina, Australia, Paraguay, and in the Indo Gangetic Plains (Derpsch, 2008).

Organic carbon content is a key indicator of soil quality (Govaerts et al. 2009; Jandl et al., 2013) and can increase in Conservation Agriculture Production Systems (CAPS). No-till, for example, has improved soil quality and fertility in Mediterranean areas in Spain (Madejón et al., 2009) and in Argentina (Diaz-Zorita et al., 2002), and slowed SOC decomposition in the United States (Mishra et al., 2010).

In Southeast Asia, conservation agriculture is still at a nascent stage. In Cambodia, several CAPS have shown great promise (Boulakia et al., 2009). In Laos, soil aggregation, water holding capacity, and biological activity were enhanced under CAPS (Tivet et al., 2008). In Vietnam, conservation agriculture on sloping lands reduced soil erosion by up to $96 \%$ and increased crop yield by more than $200 \%$ (Doanh and Tuan, 2008). In the Philippines, no extensive research has been done on the impacts of conservation agriculture on soil quality. Hence, a multi-year study was conducted to compare the effects of CAPS and a conventional plowbased system on SOC and residual water content (RWC) in selected crop production systems. This research aims to generate new knowledge and on the soil quality impacts of these farming systems to serve as basis for policy formulation and upscaling of conservation agriculture in steep upland crop production areas.

\section{Material and Methods}

This study was conducted at the Sustainable Agriculture and Natural Resources Management (SANREM) Innovation Lab research site in Claveria, Misamis Oriental, Philippines, which is located at 8०38'39" N and $124^{\circ} 55^{\prime} 49^{\prime \prime} \mathrm{E}$, and has an average land slope of $26 \%$ (Figure 1 ).

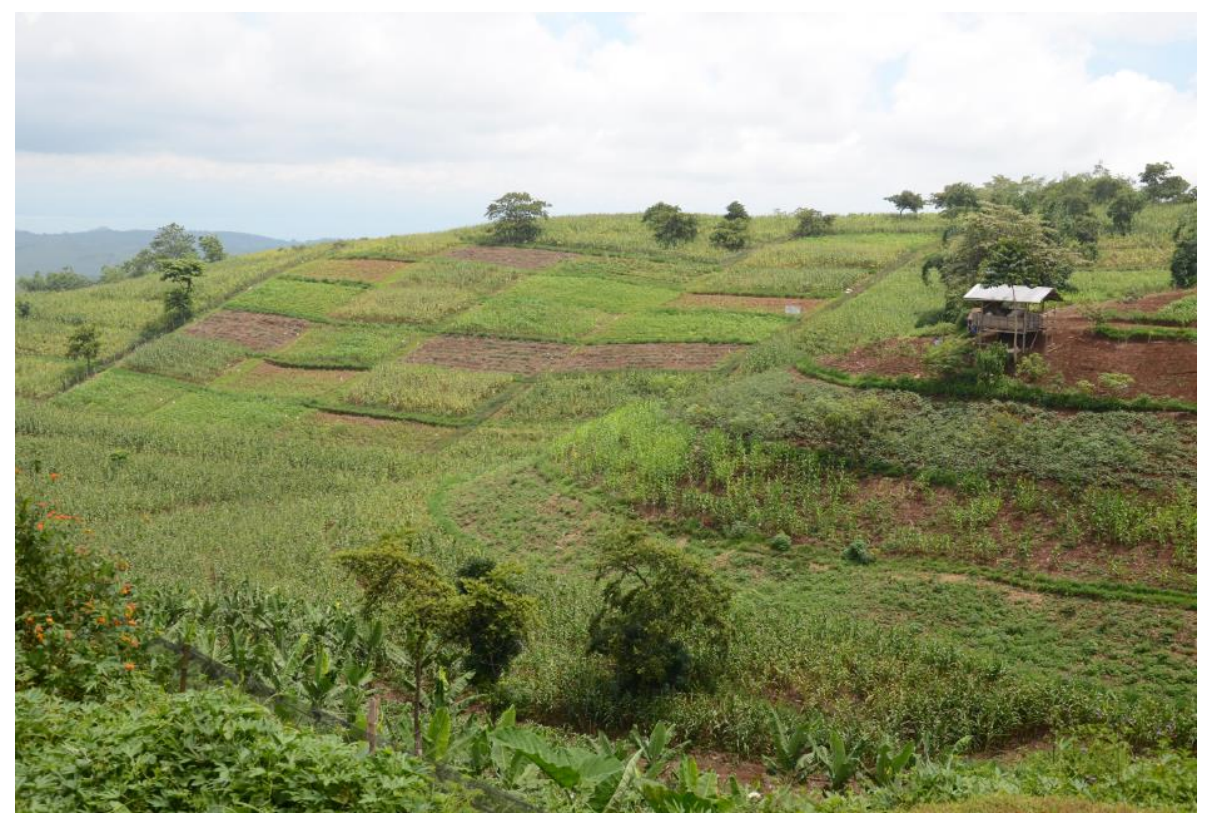

Figure 1. The SANREM research site in Claveria, Misamis Oriental, Philippines.

The area is representative of the upland agriculture landscape in northern Mindanao. Six CAPS treatments including different cropping patterns and cover crops, and a plow-based system as control (Table 1), were laid out in a randomized complete block design with four replicates and a plot size of $10 \mathrm{~m} \times 20 \mathrm{~m}$. Each treatment included subplots with high (120, 60 and $\left.60 \mathrm{~kg} \mathrm{~N} \mathrm{P} \mathrm{K} \mathrm{ha}^{-1}\right)$ and moderate (60-30-30 $\mathrm{kg} \mathrm{N} \mathrm{P} \mathrm{K} \mathrm{ha-1)}^{-1}$ fertility levels.

For treatment 1, seeds of the main crop, maize, were dibble-planted at a spacing of $70 \mathrm{~cm} \times 20 \mathrm{~cm}$ resulting in a plant density of approximately 71,000 plants ha-1. Cover crop Arachis pintoi Krapov \& W.C. Gregory cuttings were planted in a single row in the middle of maize rows every $25 \mathrm{~cm}$. In subsequent maize crops, NPK fertilizer was applied, and seeds were planted in furrows in the living Arachis pintoi mulch. For treatment 2 , maize was established and managed as in treatment 1. 
Table 1. Summary of conservation agriculture production systems treatments in Mindanao

\begin{tabular}{cc}
\hline Treatment & Cropping system \\
\hline T1 & Arachis pintoi + Maize- Arachis pintoi + Maize \\
T2 & Maize + Stylosanthes guianensis - Stylosanthes guianensis- Fallow \\
T3 & Maize + cowpea - Upland rice + cowpea \\
T4 & Maize + rice bean- Maize + rice bean \\
T5 & Cassava + Stylosanthes guianensis \\
T6 & Maize-maize (conventional plow-based) (control) \\
\hline
\end{tabular}

The seeds of cover crop Stylosanthes guianensis (Aubl.) Sw were drilled between rows of maize and thinned to 10 to 15 plants $\mathrm{m}^{-1}$. In subsequent croppings, Stylosanthes was flattened and sprayed with glyphosate before maize planting. For treatment 3, maize was established in double rows spaced $35 \mathrm{~cm}$ apart at $20 \mathrm{~cm}$ between plants resulting in a plant density of about 72,000 plants/ha, followed by two rows of cowpea (Vigna unguiculata (L.) Walp), as a cover crop, spaced $35 \mathrm{~cm}$ apart at 10 to 15 plants $\mathrm{m}^{-1}$. After the harvest of cowpea, upland rice (Oryza sativa L.) was planted. Cowpea was planted again after the maize harvest. For treatment 4, the cover crop rice bean Vigna umbellata (Thunb.) Ohwi \& H. Ohashi was first established. Two weeks later, maize was established as in treatment 1 . During subsequent cropping, rice beans and weeds were sprayed with glyphosate before maize planting. For treatment 5 , furrows were spaced at $100 \mathrm{~cm}$, and cuttings of the main crop cassava were planted $50 \mathrm{~cm}$ apart at about 20,000 plants ha-1. Seeds of the cover

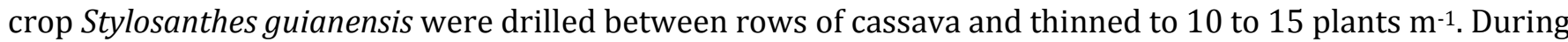
subsequent cropping, the cover crop was flattened and sprayed with glyphosate before cassava was planted. Treatment 5 represents the current practice for maize production for most farmers in the Philippines. Prior to maize planting, plowings by animal-drawn moldboard plow and two harrowings by animal-drawn spiketoothed harrow along with furrowing by animal-drawn moldboard plow were performed.

Soil samples were collected with an auger at 0 - to 5-, 5- to 15- and 15- to 30-cm depth on July 18, 2010; December 5, 2010; April 15, 2011; September 18, 2011; February 25, 2012; August 3, 2012; and September 6 , 2013. Soil samples were composited for each treatment for SOC analysis. The soil samples were brought to University of the Philippines Los Baños for laboratory analysis, and SOC was determined using the WalkleyBlack method (Walkley and Black, 1934). Changes of SOC over time were analyzed using linear regression analysis.

Soil residual water content was measured in four quadrants in each experimental plot using time domain reflectometry (TDR; Field Scout 300, Spectrum Technologies Inc., Paxinos, PA) after each cropping season in the upper $12 \mathrm{~cm}$ which likely represents the soil layer with maximum root activity. In each quadrant, the average of three TDR readings was used to represent the quadrant. The average of the four quadrant readings was then used to represent the RWC for that plot or replicate for each of the six treatments. The TDR used enabled automatic calibration with a built-in firmware unlike other TDR meters. Also, any minute error in the automatic calibration of the TDR probe should have been offset because the overall average for each plot was based on 12 measurements. Moreover, the RWC values from TDR measurements were comparable to those obtained from gravimetric measurements of the collected soil samples used for bulk density determinations. Analysis of variance of the RWC water content was consequently performed using Dunnett's two-sided tests (Dunnett, 1955).

\section{Results and Discussion}

\section{Effects of Conservation Agriculture Production Systems on SOC}

Soil organic carbon at $0-5$-cm depth in plow-based system declined over time $(\mathrm{P} \leq 0.10)$, decreasing from $3.3 \%$ at the start of the CAPS treatments to $3.1 \%$ and $2.9 \%$ for the high and moderate fertility treatments respectively after three cropping years. These results can be attributed to the disruption in $\mathrm{C}$ cycling due to tillage as previously shown (e.g., Govaerts et al., 2009; Baker et al., 2006; Murty et al., 2002; Davidson and Ackerman, 1993).

On the other hand, SOC in the CAPS treatments did not decrease temporally, regardless of fertility level, and even tended to increase to $3.8 \%$ and $3.7 \%$ for the high and moderate fertility levels, respectively, after three cropping years. The strongest effect on SOC for the high fertility level was for the CAPS treatment including maize + Stylosanthes guianensis- Stylosanthes guianensis - fallow (P = 0.07), with the treatment explaining $60 \%$ of the variance in SOC (Table 2). 
Table 2. Changes in soil organic carbon (SOC; \%) with time in days after imposing the treatments at 0 - to $5 \mathrm{~cm}$ soil depth under the high fertility level

\begin{tabular}{cccc}
\hline Treatment & Regression equation & $\mathrm{R}^{2}$ & $\mathrm{P}$ \\
\hline T1 & SOC $=3.460+0.00033$ Time & 0.23 & 0.33 \\
T2 & SOC $=3.176+0.00138$ Time & 0.60 & 0.07 \\
T3 & SOC $=3.243+0.00035$ Time & 0.25 & 0.31 \\
T4 & SOC $=3.210+0.00005$ Time & 0.02 & 0.77 \\
T5 & SOC $=3.446+0.00051$ Time & 0.25 & 0.32 \\
T6 & SOC $=3.333-0.00065$ Time & 0.54 & 0.09 \\
\hline
\end{tabular}

Treatments T1 to T6 are described in Table 1

For the moderate fertility, the CAPS treatment with cassava + Stylosanthes guianensis exhibited the highest rate of increase in SOC $(\mathrm{P}=0.01)$ and explained $82 \%$ of the variance in SOC, followed closely by the treatment with maize + Stylosanthes guianensis - Stylosanthes guianensis- Fallow (P = 0.02) (Table 3).

Table 3. Changes in soil organic carbon (SOC; \%) with time in days after imposing the treatments at 0 - to 5-cm soil depth under the moderate fertility level

\begin{tabular}{cccc}
\hline Treatment & Regression equation & $\mathrm{R}^{2}$ & $\mathrm{P}$ \\
\hline T1 & SOC $=-0.00026$ Time +3.578 & 0.14 & 0.47 \\
T2 & SOC $=0.00073$ Time +3.393 & 0.80 & 0.02 \\
T3 & SOC $=-0.00060$ Time +3.736 & 0.11 & 0.52 \\
T4 & SOC $=0.00115$ Time +3.271 & 0.59 & 0.07 \\
T5 & SOC $=0.00120$ Time +3.142 & 0.82 & 0.01 \\
T6 & SOC $=-0.00093$ Time +3.340 & 0.60 & 0.07 \\
\hline
\end{tabular}

Treatments $\mathrm{T} 1$ to $\mathrm{T} 6$ are described in Table 1

Increased SOC could relate to the large biomass production and incorporation from Stylosanthes guianensis, which was allowed to decay after each cropping. In a separate study on the same site (Mercado et al., 2012), two CAPS treatments that included Stylosanthes guianensis as a cover crop, showed the highest biomass production after two cropping seasons, with a mean value of 27.1 and 7.0 tons ha-1, respectively.

For the 5- to 15-cm and 15- to 30-cm soil depths, no distinct pattern of SOC change in the CAPS treatment was exhibited (Data not shown). Explained variance of regression functions were low (not higher than $41 \%$ with P from 0.17 to 0.99 ).

Although long-term monitoring is necessary to assessing the effects of conservation agriculture on SOC more conclusively, the foregoing results point to a positive effect in some cropping systems in a relatively short period while plow-based systems negatively impact the soil. The minimal disturbance of the soil under CAPS prevents the exposure of the soil particles to microbial attack, thereby minimizing the loss of organic matter. Moreover, the continuous presence of crop mulch cover appears to contribute to the increase in SOC. These are important positive effects that can reduce the ongoing global land degradation (Bail et al., 2008).

\section{Effects of Conservation Agriculture Production System on RWC}

Mean RWC in the CAPS treatments was higher than those in the plow-based system (Figure 2). Fertility levels did not affect RWC. After one cropping season, RWC ranged from 31 to $39 \%$ on a volume basis in the CAPS treatments, and from 25 to $31 \%$ in the plow-based system. After two and three cropping seasons, the RWC in the CAPS treatments varied from 21 to $25 \%$ and from 27 to $36 \%$, respectively, compared with 18 and $20 \%$ in the plow-based system.

The CAPS treatment with maize + Stylosanthes guianensis - Stylosanthes guianensis-fallow yielded the highest residual moisture content $(\mathrm{P} \leq 0.05)$. The significantly lower RWC under the plow-based system relative to the CAPS treatments may be attributed to the substantial soil disturbance caused by plowing at the beginning of each cropping in these plots, which loosens up the soil structure. Increased SOC in the uppermost soil layer in some of the CAPS treatments may have also contributed to higher RWC measurements as found in other studies (Balesdent et al., 2000). 


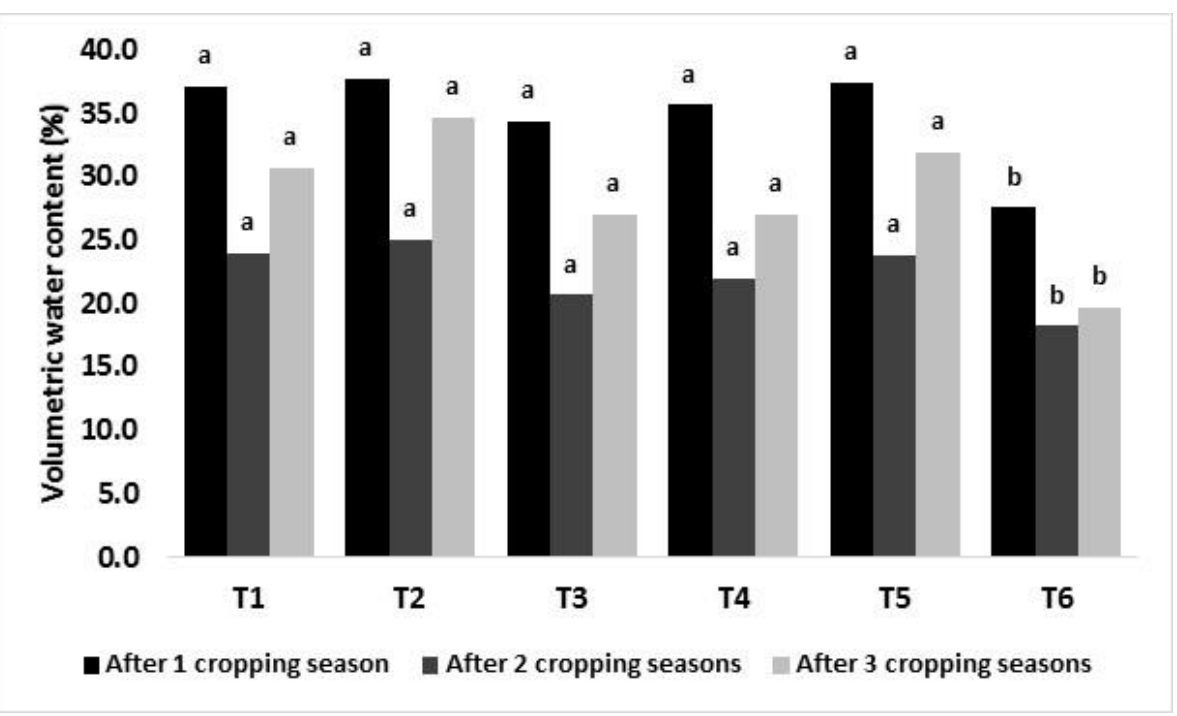

Figure 2. Residual soil water content at various CAPS treatments after one, two, and three cropping seasons.

Findings from this study indicated that conservation agriculture has a positive impact on improving the water retention capacity of the soil as found in other studies (Thierfelder and Wall, 2009; Martinez et al., 2011). Conversely, a plow-based system significantly reduces RWC. Consequently, more water is conserved under CAPS than under a plow-based system. This has practical implications in terms of the timing of the next cropping, irrigation frequencies, and the potential increased adaptation to climate change. Previous research has shown that the relationship between SOC and RWC is often not direct because of the effect of other variables such as soil textural components and bulk density (Rawls et al., 2003; Parajuli and Duffy, 2013).

\section{Conclusions}

Results of this study illustrate the potential of CAPS with no till, cover crops and crop rotations or mixtures to improve soil characteristics in steep agricultural landscapes in northern Mindanao. With CAPS, SOC generally exhibited an increase with time albeit the effect was limited to the upper part of the soil profile. In the plow-based system, SOC instead decreased with time. The high fertility level applied in this study appeared to augment the CAPS effects on SOC. The cassava crop followed by the cover crop Stylosanthes guianensis in the first year and Stylosanthes guianensis and fallow during the second year had the highest SOC increase, followed by the maize + cowpea (first year) and upland rice and cowpea (second year).

Effects of CAPS on RWC were even more marked than that those for SOC. The consistent increase in RWC over several years suggests that CAPS can have a composited effect on the soil water budget besides other positive effects such as rainwater splash and erosion reduction. Nevertheless, long-term soil quality monitoring is necessary to generate additional evidence on the impact of CAPS on soil quality. Overall, the results obtained in this study could serve as a significant takeoff point for further studies which may eventually be used for modeling studies and for policy formulation geared towards soil and water resources conservation and for sustainable upland agriculture in the humid tropics.

\section{Acknowledgements}

We are deeply grateful to USAID for funding the Southeast Asia project of the Sustainable Agriculture and Natural Resource Management Innovation Lab (SANREM).

\section{References}

Bail, Z.G., Dent, D.L., Olsson, L., Schaepman, M.E., 2008. Proxy global assessment of land degradation. Soil Use and Management 24: 223-234.

Baker, J.M., Ochsner, T.E., Venterea, R.T., Griffis, T.J., 2006. Tillage and soil carbon sequestration-what do we really know? Agriculture, Ecosystems and Environment 118: 1-5.

Balesdent, J., Chenu, C., Balabane, M., 2000. Relationship of soil organic matter dynamics to physical protection and tillage. Soil and Tillage Research 53: 215-230. 
Boulakia, S., Phâlly, K., Sona, S., Vira, L., Kimchhorn, C., 2009. Five years of adaptative research for upland DMC based cropping systems creation in Cambodia. PADAC report.

Davidson, E.A., Ackerman, I.L., 1993. Changes in soil carbon inventories following cultivation of previously untilled soils. Biogeochemistry 20: 161-193.

De Morais, J.C., 2011. Carbon sequestration, soil quality, crop profitability and environmental quality. Oral presentation at the Second International Conservation Agriculture Workshop and Conference in Southeast Asia. July 4-7. Phnom Penh, Cambodia.

Derpsch, R., 2008. No-tillage and conservation agriculture: A progress report. In: No-till Farming Systems. T. Goddard, M.A. Zoebisch, Y.T. Gan, W. Ellis, A. Watson, S. Sombatpanit (eds.). World Association of Soil and Water Conservation, Bangkok, pp. 7-39.

Diaz-Zorita, M., Duarte, G.A., Grove, J.H., 2002. A review of no-till systems and soil management for sustainable crop production in the subhumid and semiarid Pampas of Argentina. Soil and Tillage Research 65: 1-18.

Doanh, L.Q., Tuan, H.D., 2008. Conservation agriculture on sloping lands in northern mountainous regions of Vietnam. In: Proceedings of the Regional Workshop on Conservation Agriculture. M. Chanphengxay, M., M.A. Khamhung, M.K. Panysiri, M.A. Chabanne, M. F. Jullien, M.H. T. Quoc, M.P. Lienhard, M.F. Tivet (eds.) October 28 to November 1. Phonsavan, Lao PDR. pp. 27-36.

Dunnett, C.W., 1955. A multiple comparison procedure for comparing several treatments with a control. Journal of the American Statistical Association 50: 1096 -1121.

Erenstein, O., Sayre, K., Wall, P., Dixon, J., Hellin, J., 2008. Adapting no-tillage agriculture to the conditions of smallholder maize and wheat farmers in the tropics and sub-tropics. In: No-till Farming Systems. T. Goddard, M.A. Zoebisch, Y.T. Gan, W. Ellis, A. Watson, S. Sombatpanit (eds.). World Association of Soil and Water Conservation, Bangkok, pp. 253-278.

Follet, R.F., Stewart, C.E., Pruessner, E.G., Kimble, J.M., 2012. Effects of climate change on soil carbon and nitrogen storage in the US Great Plains. Journal of Soil and Water Conservation 67: 331-342.

Govaerts, B., Verhulst, N., Castellanos-Navarette, A., Sayre, K.D. Dixon J., Dendooven, L., 2009. Conservation agriculture and soil carbon sequestration: Between myth and farmer reality. Critical Reviews in Plant Sciences 28: 97-122.

Jandl, R., Rodeghiero, M., Martinez, C., Cotrufo, M.F., Bampa, F., van Wesemael, B., Harrison, R.B., Guerrini, I.A., D. Richter Jr., D., Rustad, L., K. Lorenz, K., Chabbi, A. Miglietta, F., 2013. Current status, uncertainty and future needs in soil organic carbon monitoring. Science of the Total Environment 468-469: 376-383.

Madejón, E., Murillo, J.M., Moreno, F., López, M.V., Arrue, J.L., Alvaro-Fuentes, J., Cantero, C., 2009. Effect of long-term conservation tillage on soil biochemical properties in Mediterranean Spanish areas. Soil and Tillage Research 105: 55-62.

Martinez, I., Ovalle, C., Del Pozo, A., Uribe, H., Valderrama, N., Prat, Ch., Sandoval, M., Fernández, F., Zagal, E. (2011). Influence of conservation tillage and soil wáter content on crop yield in dryland compacted alfisol of central Chile. Chilean Journal of Agriculture Research 71: 615-622.

Meehl, G.A., Stocker, T.F., Collins, W.D., Friedlingstein, P., Gaye, A.T., Gregory, J.M., Kitoh, A., Knutti, R., Murphy, J.M., Noda, J.A., Raper, S.C.B., Watterson, I.G., A.J. Weaver, A.J., Zhao, Z.C., 2007. Global climate projections. In Climate change: The physical science basis. Contribution of Working Group I to the Fourth Assessment Report of the Intergovernmental Panel on Climate Change. S. Solomon, D. Qin, M. Manning, Z. Chen, M. Marquis, K.B. Averyt, M. Tignor, H.L. Miller (eds.). Cambridge University Press, Cambridge, UK, and New York, USA.

Mercado, Jr., A.R., Ella, V.B., Reyes, M.R., 2012. Yield, biomass and soil quality of conservation agriculture systems in the Philippines. In Proceedings $3^{\text {rd }}$ International Conference on Conservation Agriculture in Southeast Asia. Hauswirth et al. (eds.), December 10-15, Hanoi, Vietnam, p. 256-58.

Mishra, U., Ussiri, D.A.N., Lal, R., 2010. Tillage effects on soil organic carbon storage and dynamics in Corn Belt of Ohio USA. Soil and Tillage Research 107: 88-96.

Murty, D., Kirschbaum, M.U.F., McMurtrie, R.E., McGilvray, H.M., 2002. Does conversion of forest to agricultural land change soil carbon and nitrogen? A review of literature. Global Change Biology 8: 105-123.

Parajuli, P.B., Duffy, S. 2013. Evaluation of soil organic carbón and soil moisture content from agricultural fields in Mississippi. Open Journal of Soil Science 3: 81-90.

Rawls, W.J., Pachepsky, Y.A., Ritchie, J.C., Sobecki, T.M., Bloodworth, H., 2003. Effect of soil organic carbon on soil water retention. Geoderma 116: 61-76.

Thierfelder Ch., Wall, P.C., 2009. Effects of conservation agriculture techniques on infiltration and soil water content in Zambia and Zimbabwe. Soil and Tillage Research 105:217-227.

Tivet, F., Quoc, H.T., Boyer, J., Chabanne, A., Inthavong, C., S. Senephansiri, S., Keodouangsy, L., Chounlamountry, T., Khamxaykhay, C., K. Panyasiri, K., Seguy, L., 2008. Soil aggregation, water holding capacity and biological activity under no-till systems and cropping sequences in the Lao PDR. In Proceedings of the Regional Workshop on Conservation Agriculture, XX (eds.). October 28 to November 1, Phonsavan, Lao PDR, p. 130.

Walkley, A., Black, I.A., 1934. An examination of the Degtjareff method for determining soil organic matter, and a proposed modification of the chromic acid titration method. Soil Science 37: 29-38. 